\title{
ANALISIS FAKTOR-FAKTOR YANG MEMPENGARUHI PRODUKTIVITAS KERJA KARYAWAN PADA BIRO PENGGADAAN JASA PT. SEMEN PADANG Tbk.
}

\author{
Abdul Latif ${ }^{1}$, Wandi Wilanda ${ }^{2}$ \\ ${ }^{1,2}$ Program Studi Teknik Industri Sekolah Tinggi Teknologi Industri (STTIND) Padang \\ Email.abdullatief@sttind.ac.id
}

\begin{abstract}
Abstrak: Produktivitas merupakan komponen penting yang harus dimiliki oleh perusahaan untuk mencapai tujuan yang telah ditetapkan. Salah satu penyebab perusahaan sulit mencapai tujuan adalah rendahnya produktivitas karyawan. Oleh sebab itu perlu suatu usaha untuk meningkatkan produktivitas karyawan karna produktivitas dapat menggambarkan tingkat efisiensi karyawan dalam bekerja. Jenis penelitian ini bersifat kuantitatif karena mengunakan data yang memerlukan perhitungan dan mengunakan analisa kualitatif untuk mendiskripsikan data-data yang sudah diperoleh sehingga akan lebih jelas data tersebut. Untuk menganalisa data penulis menggunakan metode regresi linear berganda, yaitu suatu yang digunakan metode statistik untuk mengetahui hubungan antara variabel bebas dan terikat yang dibantu dengan menggunakan program SPSS. Berdasarkan hasil uji Regresi Linear Berganda didapatkan persamaan $: Y=5,428+0,774 X 1+0,271 X 2+0,286 X 3+0,510 X 4 \quad-0,244 X 5$. Kemudian dari hasil uji Simultan (Uji F) diketahui bahwa variabel kepemimpinan, kedisiplinan, pendidikan serta pelatihan kerja, fasilitas kerja, lingkungan kerja secara bersamaan berpengaruh terhadap produktivitas kerja karyawan di biro pengadaan jasa PT. Semen Padang. Sedangkan setelah dihitung berdasarkan Koefesien Determinasi didapatkan adjusted R Square sebesar 0,779. Perhitungan ini menunjukan bahwa kepimpinan, kedisiplinan kerja, lingkungan kerja, pendidikan dan pelatihan kerja, serta fasilitas kerja secara keseluruhan berpengaruh terhadap produktivitas kerja karyawan pada biro pengadaan jasa PT. Semen Padang sebesar 79,9\%, sedangkan sebesar 21,1\% dipengaruhi oleh variabel yang tidak menjadi variabel dalam penelitian.
\end{abstract}

Kata Kunci: Produktivitas, Regresi Linear Berganda, Uji t, Uji F

\begin{abstract}
Productivity is an important component that must be owned by the company to achieve the stated goals. One of the reasons companies find it difficult to achieve their goals is low employee productivity. Therefore we need an effort to increase employee productivity because productivity can describe the level of employee efficiency at work. This type of research is quantitative because it uses data that requires calculations and uses qualitative analysis to describe the data that has been obtained so that the data will be clearer. To analyze the data the authors use the method of multiple linear regression, which is a statistical method used to determine the relationship between independent and dependent variables that are assisted by using the SPSS program. Based on the results of the Multiple Linear Regression test found the equation: $Y=5.428+0.774 X 1+0.271 X 2+0.286 X 3+0.510 X 4-$ $0.224 X 5$. Then from the results of the Simultaneous test (Test F) it is known that the variables of leadership, discipline, education and job training, work facilities, work environment simultaneously affect the work productivity of employees in the PT. Semen Padang. Meanwhile, after calculated based on the coefficient of determination obtained adjusted $R$ Square of 0.779. This calculation shows that leadership, work discipline, work environment, work education and training, and overall work facilities affect the work productivity of employees at PT. Semen Padang was $79.9 \%$, while $21.1 \%$ was influenced by variables that were not variables in the study.
\end{abstract}

Keywords: Productivity, Multiple Linear Regression, $t$ Test, F Test 


\section{PENDAHULUAN}

Produktivitas merupakan komponen penting dalam mencapai tujuan perusahaan. Setiap aktivitas di perusahaan, karyawan harus mempu meningkatkan produktivitas dalam bekerja. Produktivitas yang tinggi akan membantu perusahaan untuk mencapai tujuan secara efektif dan efisien. Sehingga sumber daya manusia memegang peranan penting untuk kelancaran pekerjaan di perusahaan (Ervil \& Nurmayuni, 2018).

Maka diperlukan suatu rangsangan untuk meningkatkan produktifitas kerja, agar memperoleh hasil untuk mencapai tujuan perusahaan. Produktivitas kerja karyawan, sangat penting dalam upaya mencapai tujuan suatu perusahaan. Produktivitas merupakan suatu kondisi Dimana karyawan suatu perusahaan dapat bekerja secara maksimal sehingga hasil suatu kerja karyawan dsesusai dengan apa yang direncanakan. Produktivitas kerja karyawan dapat di pengaruhi oleh sebelas faktor yaitu faktor pengawasan kerja, faktor kepemimpinan, faktor kompensasi, faktor lingkungan kerja, faktor pendidikan dan pelatihan, faktor disiplin kerja, faktor fasilitas kerja, beban kerja, absensi kerja, faktor fasilitas kerja, absensi kerja, beban kerja, seleksi karyawan dan tingkat perputaran karyawan. Untuk itu produktifitas kerja karyawan harus dijaga, manajemen perusahaan perlu memerhatikan kesebelas faktor tersebut (Ervil \& Rosalina, 2019). Produktivitas juga berhubungan dengan manajemen sumberdaya manusia sebagian dari manajemen yang mempelajari aktivitas sumber daya manusia dalam organisasi, mengatur karyawan sehingga tercapai tujuan yang telah ditetapkan (Ervil et al., 2018).

Tujuan penelitian ini untuk mengetahui faktor-faktor yang mempengaruhi produktivitas karyawan pada biro pengadaan jasa PT. Semen Padang. Dan Mengetahui seberapa besarnya pengaruh faktor-faktor produktivitas terhadap karyawan pada biro pengadaan jasa PT.Semen Padang.

\section{METODE PENELITIAN}

Jenis penelitian ini bersifat kuantitatif karena mengunakan data yang memerlukan perhitungan dan mengunakan analisa kualitatif untuk mendiskripsikan data-data yang sudah diperoleh sehingga akan lebih jelas data tersebut.

Secara umum, data yang diperlukan untuk menganalisa dan memecahkan permasalahan yang ada dalam penelitian ini adalah data primer. Data primer adalah data yang diperoleh secara langsung di lapangan yaitu permasalah produktivitas karyawan terhadap kinerja karyawan di biro pengadaan jasa PT.Semen Padang.

Pengumpulan data yang dilakukan dengan wawancara lansung dengan para karyawan di biro pengadaan jasa PT. semen padang, melakukan pengamatan lansung dan memngumpulkan data yang berasal dari kuesioner yang diberikan pada karyawan biro pengadan jasa PT. Semen Padang.

Untuk mencapai tujuan penelitian, maka penulis menggunakan metode sebagai berikut :

\section{Uji Validitas Dan Reliabilitas Data}

Menggunakan pengujian statistik yang ditujukan untuk pengujian kuesioner, yaitu uji validitas dan reliabilitas, dilakukan menggunakan software SPSS 17.0

\section{Uji Asumsi Klasik}

Asumsi klasik dilakukan menggunakan software SPSS 17.0. Asumsi ini digunakan untuk mengetahui apakah hasil estimasi regresi yang dilakukan terbebas dari hal yang menyebabkan hasil regresi yang diperoleh tidak valid dan tidak dapat dipergunakan sebagai dasar untuk menguji hipotesis dan penarikan kesimpulan.

\section{HASIL DAN PEMBAHASAN}

Dari hasil pengumpulan data dengan kuensioner dari beberapa responden, maka dapat dilihat karakteristik responden berdasarkan jenis kelamin pada tabel berikut: 
Tabel 1. Karakteristik Responden Berdasarkan Jenis Kelamin

\begin{tabular}{|c|c|c|}
\hline Jenis Kelamin & $\begin{array}{c}\text { Jumlah } \\
\text { Responden }\end{array}$ & $\begin{array}{c}\text { Persentase } \\
(\mathbf{\%})\end{array}$ \\
\hline Laki-Laki & 25 & $86,2 \%$ \\
\hline Perempuan & 4 & $13,8 \%$ \\
\hline Total & $\mathbf{2 9}$ & $\mathbf{1 0 0 \%}$ \\
\hline
\end{tabular}

Berdasarkan tabel 1 di atas dapat dilihat bahwa dari 20 orang responden berjenis kelamin laki-laki sebanyak 25 orang atau sebesar $86 \%$, sedangkan berjenis kelamin perempuan sebanyak 4 orang atau sebesar $13,8 \%$.

\section{Karakteristik Responden Berdasarkan Usia}

Karakteristik responden berdasarkan tingkat usia dapat dilihat pada tabel 2 berikut:

Tabel 2. Karakteristik Responden Berdasarkan Usia

\begin{tabular}{|c|c|c|}
\hline $\begin{array}{c}\text { Umur } \\
\text { (Tahun) }\end{array}$ & $\begin{array}{c}\text { Jumlah } \\
\text { Responden(Orang) }\end{array}$ & Persentase(\%) \\
\hline$<19$ & - & - \\
\hline $20-26$ & - & - \\
\hline $27-31$ & 7 & $24,1 \%$ \\
\hline $32-37$ & 9 & $31 \%$ \\
\hline $38-43$ & 8 & $27,5 \%$ \\
\hline$>43$ & 5 & $17,2 \%$ \\
\hline Total & $\mathbf{2 9}$ & $\mathbf{1 0 0 \%}$ \\
\hline
\end{tabular}

Berdasarkan tabel 2 diatas sebanyak 7 orang atau $24,1 \%$ responden memiliki usia 27-31 tahun, sebanyak 9 orang atau 31\% memiliki usia 32-37 tahun,sebanyak 8 orang atau $27,5 \%$ memiliki usia 38-43 tahun dan sebanyak 5 orang atau 17,2\% memiliki usia lebih dari 43 tahun.

\section{Karakteristik Responden Berdasarkan Pendidikan}

Karakteristik responden berdasarkan tingkat pendidikan dapat dilihat pada tabel 3 berikut:

Tabel 3. Karakteristik Responden Berdasarkan Pendidikan

\begin{tabular}{|c|c|c|}
\hline $\begin{array}{c}\text { Pendidikan } \\
\text { Terakhir }\end{array}$ & $\begin{array}{c}\text { Jumlah } \\
\text { responden } \\
\text { (orang) }\end{array}$ & Persentase\% \\
\hline SLTA & 13 & $\mathbf{4 4 , 8 \%}$ \\
\hline
\end{tabular}

\begin{tabular}{|c|c|c|}
\hline DIPLOMA & $\mathbf{1}$ & $\mathbf{3 , 4 \%}$ \\
\hline S1 & 15 & $\mathbf{5 1 , 7 \%}$ \\
\hline S2 & - & - \\
\hline S3 & - & - \\
\hline Total & 29 & $\mathbf{1 0 0 \%}$ \\
\hline
\end{tabular}

Berdasarkan tabel 3 di atas dapat dilihat bahwa sebanyak 13 orang atau 44,8\% responden merupakan tamatan SMA, sebanyak 1 orang atau $3,4 \%$ memiliki pendidikan terakhir diploma, sebanyak 10 orang atau $51,7 \%$ memiliki pendidikan terakhir strata 1 (S1).

\section{Karakteristik Responden Berdasarkan Masa Kerja}

Karakteristik responden berdasakan masa kerja (lama bekerja) dapat di lihat pada tabel 4 berikut ini:

Tabel 4. Karakteristik Responden Berdasarkan Masa Kerja

\begin{tabular}{|c|c|c|}
\hline $\begin{array}{c}\text { Lama } \\
\text { Bekerja } \\
\text { (tahun) }\end{array}$ & $\begin{array}{c}\text { Jumlah } \\
\text { Responden } \\
\text { (orang) }\end{array}$ & Persentase \% \\
\hline$<1$ & - & - \\
\hline $1-4$ & - & - \\
\hline $5-9$ & 6 & $20,7 \%$ \\
\hline $10-15$ & 17 & $58,6 \%$ \\
\hline $16-20$ & 2 & $6,8 \%$ \\
\hline $21-24$ & 2 & $6,8 \%$ \\
\hline$>25$ & 2 & $6,8 \%$ \\
\hline Total & 29 & $100 \%$ \\
\hline
\end{tabular}

Berdasarkan tabel 4 diatas dapat dilihat bahwa sebanyak 6 orang atau 20,7\% responden telah bekerja sekitar 5-9 tahun, sebanyak 17 barang atau 58,6\% responden telah bekerja sekitar 10-15 tahun. 2 orang responden atau $6,8 \%$ responden telah bekerja sekitar 16-20 tahun sebanyak 2 orang atau $6,8 \%$ responden telah bekerja sekitar 21-25 tahun. Dan sebanyak 2 orang atau $6,8 \%$ telah bekerja selama 25 tahun lebih.

Berdasarkan hasil penelitian, yang menjadi kendala utama pada produktivitas kerja biro pengadaan jasa PT. Semen Padang adalah faktor kepemimpinan, faktor pendidikan dan pelatihan, serta faktor lingkungan kerja. Oleh karena itu, rekomendasi yang dapat penulis berikan terhadap pihak biro pengadaan jasa PT. Semen Padang agar dapat memperbaiki produktivitas kerja yang berkaitan dengan kepimpinan, pendidikan dan pelatihan kerja 
dan lingkungan kerja di biro pengadaan jasa PT. Semen Padang tersebut.

Kepimpinan, pendidikan dan pelatihan kerja serta lingkungan kerja merupakan komponen yang penting dalam sebuah perusahaan karena kepimpinan, pendidikan dan pelatihan, serta lingkungan kerja yang baik akan mempengaruhi keberhasilan pencapaian tujuan organisasi yang telah di tetapkan.

Kepemimpinan yang efektif sangat diperlukan karena karena mempengaruhi keberhasilan pencapaian tujuan yang telah ditetapkan. Kemudian dalam hal meningkatkan kemampuan individu diperlukan pendidikan dan pelatihan. Melalui pendidikan dan pelatihan, individu dibekali ilmu untuk mengembangkan pengetahuan, keterampilan dan sikap sehingga dapat meningkatkan produktivitas karyawan.

Disamping pendidikan dan pelatihan, produktivitas juga dipengaruhi oleh lingkungan kerja. Lingkungan kerja yang sehat akan meningkatkan semangat karyawan dalam bekerja, dan apabila lingkungan kerja buruk akan menurunkan produktivitas karyawan dalam bekerja.

\section{KESIMPULAN}

Dari hasil pengolahan data dan analisis pada penelitian ini dapat ditarik kesimpulan sebagai berikut:

1. Hasil penelitian ini menghasilkan persamaan linear berganda $\mathrm{Y}=$ $5,428+0,774 X_{1}+0,271 X_{2}+0,286 X_{3}+0,5$ $10 X_{4}-0,244 X_{5}$ konstanta sebesar 5,428 artinya apabila tidak terjadi perubahan pada faktor yang mempengaruhi produktivitas kerja karyawan (variabel bebas ) maka 5,248 sebagai angka konstan untuk produktivitas karyawan , atau dapat juga dikatakan bawah jika variabel faktor yang mempengaruhi produktivitas kerja karyawan sebesar 5,248 maka produtivitas kerja karyawan hanya sebesar 5,248. Dan dilihat dari nilai $R$ square adalah sebesar 0,799 atau setara dengan $79,9 \%$, nilai tersebut mengindikasikan kepimpinan, kedisiplinan, fasilitas kerja, pendidikan dan pelatihan berpengaruh terhadap produktivitas kerja karyawan sebesar $79,9 \%$ pada biro pengadaan jasa PT. Semen Padang. Sedangkan 21,1\% lainnya dipengaruhi oleh faktor lain yang tidak diteliti.

2. Berdasarkan hasil pengolahan data dari 5 variabel produktivitas $\left(\mathrm{X}_{1}=\right.$ kepimpinan, $X_{2}=$ kedisiplinan, $X_{3}=$ pendidikan dan pelatihan $\mathrm{X}_{4}=$ lingkungan kerja, $\mathrm{X}_{5}=$ fasilitas kerja) terdapat 3 variabel yang berpengaruh secara signifikan yaitu :

\section{A. Kepemimpinan}

Berdasarkan pengolahan data dapat dilihat nilai $t_{\text {hitung }}$ untuk variabel kepimpinan (X1) adalah 3,940.Dengan demikian dapat dikatakan $t_{\text {hitung }} 3,940>t_{\text {tabel }} 2,069$ artinya variabel kepemimpinan (X1) memiliki pengaruh signifikan terhadap produktivitas karyawan.( artinya Ha diterima dan Ho ditolak).

B. Pelatihan dan Pendidikan

Berdasarkan pengolahan data dapat dilihat nilai $t_{\text {hitung }}$ untuk variabel pelatihan dan pendidikan (X3) adalah 2,334. Dengan demikian dapat dikatakan $t_{\text {hitung }} 2,334$ $>t_{\text {tabel }} 2,069$ artinya variabel pelatihan dan pelatihan X3 memiliki pengaruh signifikan terhadap produktivitas karyawan (artinya $\mathrm{Ha}$ diterima dan Ho ditolak).

C. Lingkungan Kerja

Berdasarkan pengolahan data dapat dinilai $t_{\text {hitung untuk variabel }}$ lingkungan kerja (X4) adalah 2,228. Dengan demikian dapat dikatakan $t_{\text {hitung }} 2,069=t_{\text {tabel }} 2,069$ artinya variabel lingkungan kerja (X4) memiliki pengaruh signifikan terhadap produktivitas karyawan. (artinya Ha diterima dan Ho ditolak). 


\section{DAFTAR PUSTAKA}

Arikunto,suharsimi, Proses Penelitian Suatu Pendekatan Pratek. Penerbit PT.Rineka Citra. Yogyakarta:2010

Buchari, Alrad. 2001. Manajemen Pemasaran dan Pemasaran Jasa. CV Alfabeta. Bandung

Ervil, R., \& Nurmayuni, D. (2018). PENJADWALAN PRODUKSI

DENGAN METODE CAMPBELL DUDEK SMITH (CDS) UNTUK MEMINIMUMKAN TOTAL WAKTU PRODUKSI (MAKESPAN). Saint Dan Teknologi, 18(1), 13-17. Retrieved from http://ojs.sttind.ac.id/sttind_ojs/index. php/Sain/article/view/93/68

Ervil, R., \& Rosalina, M. (2019). ESTIMASI PERMINTAAN AIR MINUM DALAM KEMASAN AYIA CUP 240 ML PADA PT . GUNUNG NAGA MAS. Pendidikan Teknologi Kejuruan, 2(2), 67-73. Retrieved from http://jptk.ppj.unp.ac.id/index.php/jpt k/article/view/200/41

Ervil, R., Zulfahli, R., Industri, T., Tinggi, S., Industri, T., \& Series, T. (2018). Analisis Kerusakan Sparepart Pada Mesin Planetary Cooler Untuk Menghitung Biaya Sparepart Yang Rusak Pada Indarung Ii / Iii Di Pt . Semen Padang. Saint Dan Teknologi, 18(2), 97-101. Retrieved from http://ojs.sttind.ac.id/sttind_ojs/index. php/Sain/article/view/118/88

Ghozali, Imam, Aplikasi Analisis Multivariate dengan Program SPSS, Badan

Hasibuan, S.P Malayu. Manajemen Sumber Daya Manusia. PT. Bumi Aksara. Jakarta. 2008.
Hasibuan, S.P Malayu. Organisasi dan Motivasi, PT. Bumi Aksara. Jakarta. 2010.

Isyandi. Manajemen Sumber Daya Manusia Dalam Perspektif Global, Pekanbaru: Unri Press, Pekanbaru 2004

Kaswan. Pelatihan dan Pengembangan, PT. Alfabeta. Bandung: 2011

Kartono, Kartini. Pemimpin dan Kepemimpinan. Jakart:Rajawali. (2002).

Muchdarsyah Sinungan, Produktivitas Apa dan Bagaimana, PT. Bumi Aksara, Jakarta 2009.

Nitisemito. Alex S. Manajemen Personalia Edisi Revisi.: Ghalia Indonesia. Jakarta 2002

Rivai, Veithzal. Manajemen Sumber Daya Manusia Untuk Perusahaan,PT. Raja Grafindo Persada,Jakarta,2004.

Robbins, Stephen P, Organizational Behavior,New Jersey,prentice, Haall, 2003.

Sedarmayanti, Tata Kerja Dan Produktivitas Kerja, Mandar Maju, Bandung. 2000

Siagian, Sondang MPA,. Manajemen Sumber Daya Manusia, Bumi Aksara, Jakarta. 2001

Sugiyono. Metode Penelitian Bisnis, Alfabeta,2009

Suad Husnan dan Ranu pandojo, Heidjrachman.. Manajemen Personalia. Yogyakarta : BPFE. 2002

Sofyan. Syafri. Akuntansi Keperilakuan. Andi Offset. Yogyakarta. 2001 
Umar,Husein, Metode Penelitian untuk

Skripsi dan Tesis Bisnis,Edisi

Kedua,PT.Raja Grafindo

Persada,Jakarta,2011. 